\title{
Therapeutic potential of fucoidan in the reduction of hepatic pathology in murine schistosomiasis japonica
}

\author{
Xueqi Bai ${ }^{1}$, Maining $\mathrm{Li}^{1}$, Xinyue Wang ${ }^{1}$, Hao Chang ${ }^{1}$, Yangyue $\mathrm{Ni}^{1}$, Chen $\mathrm{Li}^{1}$, Kaiyue He ${ }^{1}$, Huiquan Wang ${ }^{1}$, \\ Yuxuan Yang ${ }^{1}$, Tian Tian' ${ }^{2}$, Min Hou ${ }^{1}$, Minjun $\mathrm{Ji}^{1 *}$ and Zhipeng $\mathrm{Xu}^{1 *}$
}

\begin{abstract}
Background: Hepatic granuloma formation and fibrosis as the consequence of tissue entrapped eggs produced by female schistosomes characterize the pathology of Schistosoma japonicum infection. It has been proposed that fucoidan, a sulfated polysaccharide existing naturally in brown seaweed Fucus vesiculosus, plays a diversified role to perform immunomodulatory activities. However, whether fucoidan functions in the host hepatic pathology is unknown and identifying the potential mechanism that is responsible for hepatic improvement is still necessary.
\end{abstract}

Methods: We evaluated the hepatic pathology from S. japonicum-infected mice after treatment with fucoidan. qRTPCR and immunofluorescence were used to detect the pro- or anti-inflammatory factors and the phosphorylated p65 in the livers. In addition, flow cytometry was also performed to investigate the T cell subsets in the S. japonicuminfected mice after treatment with fucoidan, and functional molecules relatively specific to Treg cells were detected in vitro. Furthermore, macrophages were treated with fucoidan in vitro and to detect the inflammatory cytokines.

Results: Treatment with fucoidan significantly reduced the hepatic granuloma size and fibrosis response during $S$. japonicum infection. The attenuated phospho-p65 protein levels and the mRNA levels of pro-inflammatory cytokines (IL-6, IL-12 and TNF-a) were observed in the livers from fucoidan-treated S. japonicum-infected mice; however, the mRNA levels of anti-inflammatory cytokines (IL-4 and IL-13) were increased. In addition, the infiltration of Treg cells was significantly enhanced both in the livers and spleens from fucoidan-treated S. japonicum-infected mice. Consistent with this, the mRNA levels of IL-10 and TGF- $\beta$ were dramatically increased in the livers from S. japonicum-infected mice after fucoidan treatment. Furthermore, in vitro stimulated splenocytes with fucoidan resulted in increasing Treg cells in splenocytes as well as the functional expression of CC chemokine receptor type 4 (CCR4) and CXC chemokine receptor type 5 (CXCR5) in Treg cells. Additionally, fucoidan promoted the mRNA levels of IL-4 and IL-13 in macrophages.

Conclusions: These findings suggest an important role of natural fucoidan in reducing hepatic pathology in the progress of S. japonicum infection with a stronger Treg response, which may reveal a new potential therapeutic strategy for hepatic disease caused by parasitic chronic infection.

Keywords: Granuloma, Fibrosis, Fucoidan, Treg, Schistosoma japonicum

\footnotetext{
*Correspondence: jiminjun@njmu.edu.cn; zhipengxu@njmu.edu.cn

1 Department of Pathogen Biology, Jiangsu Province Key Laboratory

of Modern Pathogen Biology, Nanjing Medical University, Nanjing, Jiangsu 211166, China

Full list of author information is available at the end of the article
}

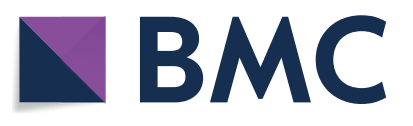

(c) The Author(s) 2020. This article is licensed under a Creative Commons Attribution 4.0 International License, which permits use, sharing, adaptation, distribution and reproduction in any medium or format, as long as you give appropriate credit to the original author(s) and the source, provide a link to the Creative Commons licence, and indicate if changes were made. The images or other third party material in this article are included in the article's Creative Commons licence, unless indicated otherwise in a credit line to the material. If material is not included in the article's Creative Commons licence and your intended use is not permitted by statutory regulation or exceeds the permitted use, you will need to obtain permission directly from the copyright holder. To view a copy of this licence, visit http://creativeco mmons.org/licenses/by/4.0/. The Creative Commons Public Domain Dedication waiver (http://creativecommons.org/publicdomain/ zero/1.0/) applies to the data made available in this article, unless otherwise stated in a credit line to the data. 


\section{Background}

Schistosomiasis, caused by the parasite of the genus Schistosoma, is a chronic helminth disease remaining in tropical and subtropical developing countries [1]. The main pathological manifestations of schistosomiasis japonica are granuloma and subsequent fibrosis due to lodged worm eggs, resulting in irreversible, lethal impairment in the host liver and intestine [2, 3]. Numerous studies suggested that the subsets of $\mathrm{CD} 4^{+} \mathrm{T}$ cells play critical roles in regulating hepatic immune pathology during Schistosoma japonicum infection. A type-2 helper $\mathrm{T}$ (Th2) immune response is initially evoked at a low level to keep Th1 inflammatory pathology in check during the acute stage [4], however, it turns out an interleukin-4 (IL4)/IL-13-driven granulomatous response chronically [2]. Th17 cells also function during the late infection stage together with Th2 cells [2]. Notably, CD $4^{+} \mathrm{CD} 25^{+}$Foxp $3^{+}$ regulatory $\mathrm{T}$ (Treg) cells have been demonstrated to diminish excessive Th2 anti-egg response in a transforming growth factor- $\beta$ (TGF- $\beta$ )- and-IL-10-dependent manner, thus reducing schistosome egg-induced hepatic immune pathology [5, 6].

Macrophages act as a key cell population during the development of liver fibrosis in schistosomiasis japonica. Studies have identified that macrophages were recruited specifically to the developing egg-induced granuloma in the liver and account for a prominent constituent as much as 30\% [7]. Importantly, consistent with egg deposition promoting Th2 responses, macrophages are observed to be an alternatively activated phenotype (M2) rather than a classically activated one (M1) with observed upregulation of Arg-1, Ym-1, Fizz-1 and downregulation of IFN- $\gamma$ during the chronic phase of the infection $[2,8,9]$. In addition, M2 macrophages play crucial roles in the immune response in that they can contribute to Th2-type responses and are essential for the downmodulation of Th1 responses [10, 11]. More thought-provoking evidence is that macrophages express high levels of TGF- $\beta$ and IL-10, simultaneously increase the proportion of $\mathrm{CD} 4{ }^{+} \mathrm{CD} 25^{+} \mathrm{Foxp} 3^{+}$Treg cells during S. japonicum infection [5].

Fucoidan, which is extracted mainly from brown marine algae, is a polysaccharide containing substantial L-fucose and sulfate ester groups [12]. It is well established that fucoidan has been reported to show various biological activities both in vivo and vitro such as anti-lipid accumulation and anti-tumor [13, 14], as well as anti-inflammatory immune responses [15]. Recent study has shown that fucoidan inhibited LPSinduced inflammation in macrophages by blocking the toll-like receptor-4 (TLR4) nuclear factor- $\mathrm{kB}(\mathrm{NF}-\mathrm{kB})$ signal pathway [16]. Fucoidan significantly reduced expressions of cytokines (TIMP-1, CXCL1, MCP-1 and MIP-2), consequently attenuated pneumonia and lung fibrosis in a mice model [17]. However, whether fucoidan could impact on the inflammation-associated hepatic pathologies remains unclear.

In this study, we show that the natural biological product-derived fucoidan exerts anti-hepatic pathology and anti-inflammatory activity, which is associated with the inducing hepatic Treg cells. Our study suggests a new potential therapeutic strategy at the acute phase of schistosomiasis may result in a mild course of murine schistosomiasis and can be a promising complementary treatment, reverting sequelae of such infection.

\section{Methods}

\section{Animals and parasites preparation}

Six-week-old female C57BL/6 mice obtained from the Animal Core Facility of Nanjing Medical University were bred in a specific pathogen-free (SPF) environment.

Oncomelania hupensis snails infected with S. japonicum from which cercariae were collected, were the kind gifts provided by the Jiangsu Institute of Parasitic Diseases (Wuxi, Jiangsu, China).

\section{Schistosoma japonicum infection and experimental animal model}

Twenty mice were weighed and randomly divided into four groups ( $n=5$ for each group) labeled with Ctrl (normal mice without any treatment), Ctrl + Fuco (normal mice with fucoidan treatment), Infection (S. japonicum infection without any treatment), and Infection + Fuco (S. japonicum infection with fucoidan treatment), respectively.

Mice in the Infection and Infection + Fuco groups were infected percutaneously with $12 \mathrm{~S}$. japonicum cercariae on day 0 . Since the third-week post-infection (day $21)$, mice in the Ctrl + Fuco group and Infection + Fuco group were treated with fucoidan (from Fucus vesiculosus, Sigma-Aldrich, St Louis, MO, USA) dissolved in phosphate-buffered saline (PBS) via intragastric administration $(500 \mathrm{mg} / \mathrm{kg}$ per 2 days) as suggested in a previous study [17]. Meanwhile, mice in the Ctrl group and Infection group were given the equivalent volume of sterile PBS for 6 weeks, following the same schedule that was used for the other groups. Mice were euthanized via diethyl ether-induced anesthesia at the 9th-week postinfection (Fig. 1a).

\section{Liver pathology examination}

The livers from each group was perfused with perfusion buffer $(0.85 \%(\mathrm{w} / \mathrm{v}) \mathrm{NaCl}$ plus $1 \%(\mathrm{w} / \mathrm{v})$ trisodium citrate) and the hepatic tissue derived from right lobes were collected and fixed in $4 \%$ neutralized formaldehyde and embedded in paraffin. Liver sections $(5 \mu \mathrm{m})$ were 
dewaxed and stained with hematoxylin and eosin (H\&E) for granulomas analysis or Sirius Red (Sigma-Aldrich) for fibrosis analysis.

For each group, 30 random single-egg granulomas around the single egg (6 granulomas each mouse) were calculated using AxioVision Rel 4.7 (Carl Zeiss, Hallberg moss, Germany). Granuloma sizes $(\times 100)$ are expressed as means of areas measured in $\mathrm{mm}^{2} \pm \mathrm{SD}$.

Thirty random digital images $(\times 100)$ were captured from collagen-specific Sirius red-stained slides of each group. The degree of fibrosis was evaluated histologically by measuring the intensity of fibrosis using Image-Pro Plus v6.0 (Media Cybernetics, Silver Spring, MD, USA). Integral optical density by the image area was divided to determine the mean optical density of collagen.

\section{Immunofluorescence}

Immunocytochemical staining was used to detect phospho-NF-kB p65 expression. Frozen liver sections were fixed with $4 \%$ ice-cold paraformaldehyde and washed three times in $1 \times$ PBS. Tissues were permeabilized with $0.5 \%$ Triton X-100 at room temperature for 30 min. 2\% Bovine Serum Albumin (Sigma-Aldrich) was used to block unspecific binding sites for $1 \mathrm{~h}$. Then tissues were incubated with antibodies against phosphop65 (Cell Signaling Technology, Danvers, MA, USA) at 1:200 dilution at $4{ }^{\circ} \mathrm{C}$ overnight. Following three washes with PBS, the samples were incubated with PE-conjugated goat anti-rabbit IgG antibody (Cell Signaling Technology) at a 1:200 dilution at room temperature for $2 \mathrm{~h}$. Subsequently, tissues were counterstained with DAPI (Abcam, Cambridge, MA, USA) for nucleus staining.

To detect the expression of CD4 ${ }^{+}$Foxp $3^{+}$Treg cells, frozen liver sections were fixed and permeabilized following the procedure mentioned above. After 1\% Bovine Serum Albumin (Sigma-Aldrich) was used to block unspecific binding sites for $1 \mathrm{~h}$, the liver tissues were incubated with antibodies against CD4-FITC (eBioscience, San Diego, CA, USA; at 1:20 dilution) and Foxp3PE (eBioscience; at 1:20 dilution) for $2 \mathrm{~h}$. Subsequently, tissues were washed and counterstained with DAPI (Abcam) for nucleus staining.

Images were acquired with AxioVision Rel 4.7 (Carl Zeiss). Quantification of fluorescence was achieved by Image Pro Plus software v6.0 (Media Cybernetics).

\section{Lymphocyte isolation}

To prepare splenocytes, spleens were ground in incomplete RPMI 1640 medium (Gibco, Grand Island, NY, USA). Red blood cells (RBCs) were lysed with an RBC lysis solution (Sigma Aldrich). After being washed in staining buffer containing PBS with $1 \%$ fetal bovine serum (FBS), cells were filtered through 200-gauge mesh and collected.

Hepatic lymphocytes were prepared as described previously with some modifications [18]. The remaining hepatic tissues were washed in D-Hank's solution (Invitrogen, Carlsbad, CA, USA) via the portal vein, cut into pieces and digested in $20 \mathrm{mg}$ Collagenase B (Invitrogen) at $37{ }^{\circ} \mathrm{C}$ for $45 \mathrm{~min}$. The digested tissues were then minced in a homogenized washing buffer containing $1 \times$ PBS with $1 \%$ FBS and collected. Hepatocytes were sedimented by centrifugation at $300 \times g$. The remaining cells were separated into 4 layers by centrifugation at $500 \times g$ on a $35 \%$ Percoll (Sigma-Aldrich) gradient. Lymphocytes on the second layer were subsequently centrifuged at $250 \times g$, resuspended in RBC lysis buffer and washed by complete RPMI 1640 medium. Finally, cells were passed through Pre-Separation Filters $(20 \mu \mathrm{m}$; Miltenyi Biotec, Bergisch Gladbach, Germany) and were collected for further study.

\section{Cell culture and in vitro treatment}

Splenocytes were purified from 6-week-old normal C57BL/6 mice as previously described [10]. They were cultured in 6-well plates $\left(2 \times 10^{6}\right.$ per well $)$ in RPMI 1640 medium supplemented with $10 \%$ FBS and $1 \%$ penicillin/streptomycin $(10,000 \mathrm{U} / \mathrm{ml}$ penicillin and 10 $\mathrm{mg} / \mathrm{m}$ streptomycin).

RAW264.7 cells were purchased from the Cell Bank of Chinese Academy of Sciences. Cells were spread into 6 -well plates equally $\left(2 \times 10^{6}\right.$ per well), and cultured in DMEM (Gibco) with $10 \%$ FBS and $1 \%$ penicillin/streptomycin $(10,000 \mathrm{U} / \mathrm{ml}$ penicillin and $10 \mathrm{mg} / \mathrm{ml}$ streptomycin).

Cells were incubated with or without fucoidan $(30 \mu \mathrm{g} /$ $\mathrm{ml}$ ) at $37{ }^{\circ} \mathrm{C}$ with $5 \% \mathrm{CO}_{2}$ for $24 \mathrm{~h} \mathrm{[19].} \mathrm{Then,} \mathrm{cells} \mathrm{were}$ collected for further analysis.

\section{RNA extraction and quantitative RT-PCR (qRT-PCR)}

Total RNA of tissue or cells was extracted using TRIzol Reagent (Invitrogen), and measured using a NanoDrop 2000 spectrophotometer (Thermo Fisher Scientific, Waltham, MA, USA). Complementary DNA was synthesized using HiScript Q RT SuperMix (Vazyme, Nanjing, China). Quantitative real-time polymerase chain reaction (qRT-PCR) was performed using Power SYBR Green PCR Master Mix (Applied Biosystems, Foster City, CA, USA) with the Applied Biosystems ${ }^{\mathrm{TM}}$ QuantStudio $^{\mathrm{TM}}$ 5 system. The cycling parameters were as follows: hold stage, $95^{\circ} \mathrm{C}$ for $3 \mathrm{~min}$; PCR stage, 40 cycles of $95^{\circ} \mathrm{C}$ for $10 \mathrm{~s}$ and $60^{\circ} \mathrm{C}$ for $30 \mathrm{~s}$; melt curve stage, $95{ }^{\circ} \mathrm{C}$ for $15 \mathrm{~s}$ and $60{ }^{\circ} \mathrm{C}$ for $1 \mathrm{~min}$, which was concluded by the melting curve analysis process. Triplicate PCR reactions were 
a

Infection

PBS or $0.5 \mathrm{~g} / \mathrm{kg}$ Fucoidan per 2 days

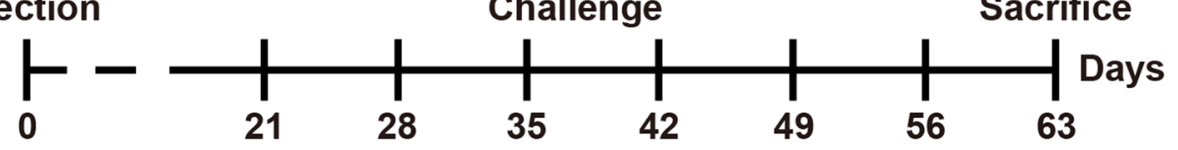

b

Ctrl

Infection
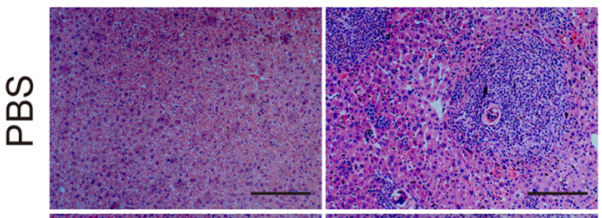

엄
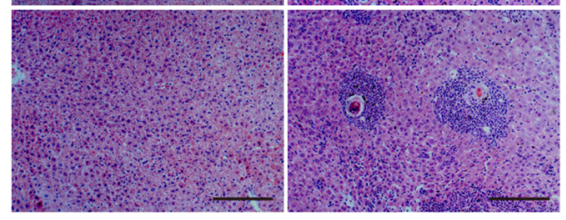

d

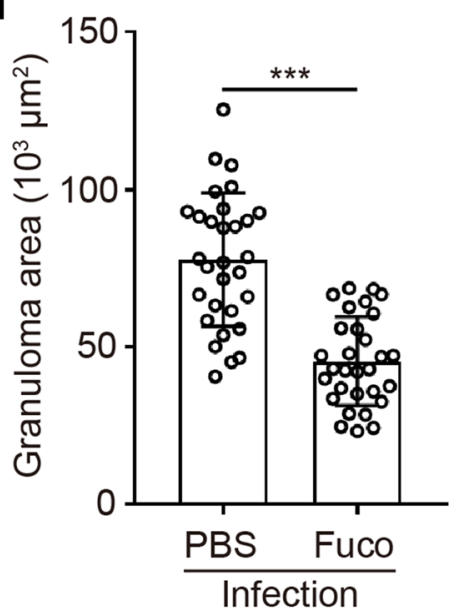

c Ctrl

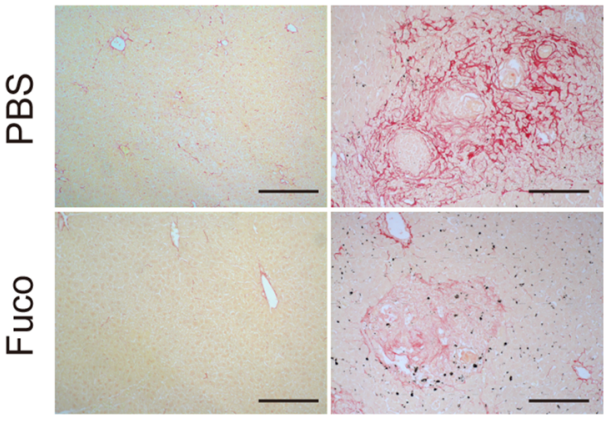

e

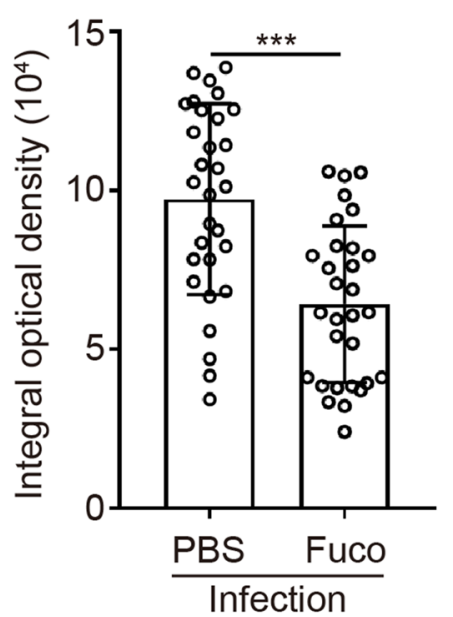

Fig. 1 Hepatic pathology was detected after fucoidan treatment during S. japonicum infection. a Experimental procedure of S. japonicum-infected model. Initially infected with S. japonicum cercariae percutaneously on day 0 , mice were treated with fucoidan or PBS by intragastric administration, $500 \mathrm{mg} / \mathrm{kg}$ per 2 days since day 21. Mice were sacrificed at 8 weeks for further study. b, d Paraffin-embedded liver sections were stained with hematoxylin and eosin (H\&E). Original magnification: $\times 100$. For each group, the sizes of 30 liver granulomas around single eggs (six random granulomas in each mouse) were qualified with AxioVision Rel 4.7. c, e Paraffin-embedded sections were stained with Sirius Red. Original magnification: $\times 100$. The mean optical density of collagen fibers by Sirius Red was digitized and analyzed by Image-Pro-Plus 6.0 software. Data are expressed as the mean \pm SD for each group ( $n=5$ for each group), and all experiments were performed twice with similar results. ${ }^{*} P<0.05$, ${ }^{*} P<0.01,{ }^{* *} P<0.001$ (Student's t-test). Scale-bars: b, c, $20 \mu \mathrm{m}$

performed for each sample. The murine housekeeping gene GAPDH was used to normalize the gene expression using a comparative method $\left(2^{-\Delta \Delta C q}\right)[10]$. The primers were designed by Primer Premier 5 software (Premier Biosoft, San Francisco, CA, USA). All primer sequences are listed in Additional file 1: Table S1.

\section{Flow cytometry}

Flow cytometry was conducted as previously described with some modifications [10]. The following antibodies were used for flow cytometry: CD3e-PerCP-Cyanine5.5; CD4-FITC; CD25-APC; IFN- $\gamma$-PE; IL-4-PE; IL-17A-PE; Foxp3-PE; PD-1-PE; KLRG1-PE (all from eBioscience, 
San Diego, CA, USA); CXCR5-PerCP-Cyanine5.5 (BD Pharmingen, San Jose, CA, USA); ICOS-BV421 (BD Pharmingen); and CCR4-PE (BioLegend, San Diego, CA, USA).

To identify Th cell subsets, $2 \times 10^{6}$ cells $/ \mathrm{ml}$ were cultured in RPMI 1640 containing 10\% FBS, and activated by leukocyte activation cocktail with GolgiPlug (BD Pharmingen) for $6 \mathrm{~h}$ at $37{ }^{\circ} \mathrm{C}$ in $5 \% \mathrm{CO}_{2}$. After the incubation, cells were harvested and labeled with surface molecules CD3e-PerCP-Cyanine5.5 (1:200) and CD4FITC (1:200). After that, cells were washed, fixed and permeabilized by cytofix/cytoperm plus fixation/permeabilization kit (BD Pharmingen), and intracellularly stained with antibodies against IFN- $\gamma$-PE, IL-4-PE, or IL17A-PE (1:50), respectively.

To identify Treg cells, $2 \times 10^{6}$ cells were labeled with CD4-FITC (1:200), CD25-APC (1:100) for $30 \mathrm{~min}$, and then washed, fixed, and permeabilized with fixation-permeabilization buffer (eBioscience). Subsequently blocked by Fc receptor binding inhibitor (eBioscience), cells were intracellularly stained with the antibody against Foxp3PE (1:50).

To identify suppression function on Treg cells, cells were harvested after $24 \mathrm{~h}$ in vitro treatment with fucoidan and labeled with CD4-FITC, CD25-APC for $30 \mathrm{~min}$. Meanwhile, cells were stained with antibodies against surface markers, including CCR4-PE, CXCR5PerCP-Cyanine5.5, PD-1-PE, ICOS-BV421, or KLRG1PE (1:100), respectively.

Flow cytometry was conducted using a BD FACSVerse ${ }^{\mathrm{TM}}$ cytometer (BD Pharmingen) followed by data analysis by FlowJo software (TreeStar Inc., Ashland, OR, USA).

\section{Statistical analysis}

Data obtained from this study are expressed as the mean \pm standard deviation (SD). GraphPad Prism v8.0 (GraphPad Software, San Diego, California, USA) was used in statistical analysis. Significant differences between the two experimental groups were identified by unpaired Student's t-test. Multiple comparisons were performed by one-way analysis of variance (ANOVA) and the leastsignificant difference (LSD) between every two groups. A value of $P<0.05$ was considered statistically significant. Significant differences are indicated as follows: ${ }^{*} P<0.05$; ${ }^{* *} P<0.005 ;{ }^{* * *} P<0.001$.

\section{Results}

Fucoidan alleviates hepatic pathology during S. japonicum infection

Since manifestations such as anti-egg granulomatous responses and fibrosis deposition are typical during $S$. japonicum infection [1], HE and Sirius Red staining were used to investigate the impact of fucoidan on these hepatic pathologies (Fig. 1a). The staining results demonstrated that the mean area of isolated granuloma was significantly declined in $S$. japonicum-infected mice with fucoidan treatment $\left(\mathrm{t}\right.$-test; $\left.t_{(58)}=6.948, P<0.0001\right)$ (Fig. 1b, d). In addition, the decrease in granuloma size was accompanied by a decrease in fibrosis in fucoidantreated mice, as shown by Sirius Red stained sections (t-test; $t_{(58)}=4.652, P<0.0001$ ) (Fig. 1c, e). These results suggest that fucoidan played a critical role in moderating hepatic pathology during S. japonicum infection.

\section{Fucoidan downregulates hepatic inflammation in $S$. japonicum-infected mice}

We next examined whether fucoidan treatment was associated with the infiltration of inflammatory cells in the livers from $S$. japonicum-infected mice. We found that the hepatic mRNA levels of IL-6, IL-12, TNF- $\alpha$, IL-4 and IL-13 were significantly elevated in the $S$. japonicum-infected mice, relative to that in the control group (ANOVA test; IL-6: $F_{(3,28)}=43.52, P<0.0001$; IL-12: $F_{(3}$, ${ }_{23)}=45.33, P<0.0001$; TNF- $\alpha: F_{(3,24)}=69.21, P<0.0001$; IL-4: $F_{(3,18)}=23.74, P<0.0001 ;$ IL-13: $F_{(3,28)}=34.52$, $P<0.0001$ ) (Fig. 2a-e). However, the production of proinflammatory cytokines (IL-6, IL-12 and TNF- $\alpha$ ) in the liver tissues was significantly reduced in the fucoidantreated S. japonicum-infected mice (Fig. 2a-c), while increased mRNA expression of anti-inflammatory cytokines (IL-4 and IL-13) was observed (Fig. 2d, e).

Given that NF- $\mathrm{kB}$ played a crucial role in the regulation of hepatic inflammation [20], we further investigated the expression of p-p65 (phospho-Ser536) in $S$. japonicum-infected mice with or without fucoidan treatment (Fig. 2f, g). The protein expression of hepatic p-p65 was significantly enhanced in the liver of $S$. japonicuminfected mice (ANOVA test; $F_{(3,20)}=80.21, P<0.0001$ ). Meanwhile, treatment with fucoidan led to less p-p65 infiltration in the $S$. japonicum-infected mice, suggesting that fucoidan may play a key role in the inhibition of the NF- $\mathrm{kB}$ signaling pathway and inflammatory cytokine production. Altogether, these data demonstrate that fucoidan can drive cells biased towards anti-inflammatory immunophenotype in the liver via inhibiting the NF-кB signaling pathway during S. japonicum infection.

\section{Total $\mathrm{CD}^{+} \mathrm{CD}^{+}{ }^{+} \mathrm{T}$ cells are independent of fucoidan in S. japonicum-infected mice}

As reported, adaptive $\mathrm{CD} 4^{+} \mathrm{T}$ cells are highly involved in immunopathology and the regulation of inflammation in schistosomiasis [21]. Thus, we next investigated whether total $\mathrm{CD}^{+} \mathrm{CD}^{+} \mathrm{T}$ cells were regulated after fucoidan treatment during S. japonicum infection. As is shown 
in Fig. 3, Additional file 2: Figure S1, compared with the untreated control group, both percentage (ANOVA test; liver: $F_{(3,8)}=26.00, P=0.0002$; spleen: $F_{(3,13)}=35.32$, $P<0.0001$ ) and absolute number (ANOVA test; liver: $F_{(3,}$ ${ }_{8)}=18.81, P=0.0006$; spleen: $\left.F_{(3,13)}=18.81 P=0.0001\right)$ of $\mathrm{CD}^{+} \mathrm{CD}^{+} \mathrm{T}$ cells in livers and spleens were dramatically increased in the $S$. japonicum-infected mice. However, neither percentage nor the absolute number of $\mathrm{CD}^{+}{ }^{+} \mathrm{T}$ cells changed after stimulated with fucoidan during S. japonicum infection in livers or spleens. These data corroborate that the effects of fucoidan attenuating hepatic pathology may have little association with the total $\mathrm{CD}^{+} \mathrm{CD}^{+}{ }^{+} \mathrm{T}$ cell proliferation in the liver and spleen from $S$. japonicum-infected mice.

\section{Fucoidan triggers Treg and Th2 cell responses in S. japonicum-infected mice}

We next illustrated whether treatment with fucoidan affects the $\mathrm{CD}^{+}{ }^{+} \mathrm{T}$ cell subsets during $S$. japonicum infection. By using immunofluorescence (Fig. 4a), we found the upregulation of $\mathrm{CD} 4{ }^{+}$Foxp $3{ }^{+}$Treg cells in the hepatic granulomas (ANOVA test; $F_{(3,8)}=76.40, P<0.0001$ ) from fucoidan-treated $S$. japonicum-infected mice. Results also showed that Treg responses were significantly enhanced in spleens (ANOVA test; percentage in spleens: $F_{(3}$, 11) $=28.04, P<0.0001$; absolute number in spleens: $F_{(3}$, $11)=57.30, P<0.0001)($ Fig. $4 \mathrm{c}, \mathrm{d})$, which was in accordance with the previous study that Treg cells played critical roles in regulating the development of immunopathology in schistosomiasis [18]. Moreover, there was also a trend for increased Th2 cells after fucoidan treatment (ANOVA test; percentage in livers: $F_{(3,8)}=73.05$, $P<0.0001$; in spleens: $F_{(3,11)}=90.83, P<0.0001$; absolute number in livers: $F_{(3,8)}=195.9, P<0.0001$; in spleens: $F_{(3 \text {, }}$ 11) $=73.49, P<0.0001$ ) (Fig. 4c, g), whilst Th1 responses were considerably reduced (ANOVA test; percentage in livers: $F_{(3,8)}=18.79, P=0.0006$; in spleens: $F_{(3,11)}=15.63$, $P<0.001$; absolute number in livers: $F_{(3,8)}=41.77$, $P<0.0001$; in spleens: $F_{(3,11)}=45.48, P<0.0001$ ) (Fig. $4 \mathrm{c}$, f). However, proportions or absolute numbers of Th17 cells in the spleens did not expand (Fig. 4c, e). Taken together, these phenomena suggest that fucoidan could play an imperative role in regulating $\mathrm{CD} 4^{+} \mathrm{T}$ cell subsets during S. japonicum infection, involving a mechanism of Treg and Th2 cell inducement.

\section{Fucoidan induces Treg and Th2 cell response in vitro}

To further confirm the role of fucoidan in $\mathrm{CD}^{+} \mathrm{T}$ cell immune responses, splenocytes from normal WT mice were stimulated with fucoidan in vitro before flow cytometry analysis. Consistent with the in vivo data, in vitro treatment splenocytes with fucoidan led to an increase in Treg and Th2 cells and a decrease in Th1 cells ( $\mathrm{t}$-test; Treg: $t_{(8)}=5.983, P=0.0003$, Th2: $t_{(8)}=4.628, P=0.002$, Th1: $t_{(8)}=11.77, P<0.0001$ ) (Fig. $5 \mathrm{a}, \mathrm{c}, \mathrm{d}$ ). Additionally, the proportion of Th17 cells was undifferentiated between PBS and fucoidan-treated groups (Fig. 5b).

Fucoidan-induced immunosuppressive activity in Treg cells Treg cells have been widely acknowledged to suppress immune responses by secreting cytokines such as IL-10 and TGF- $\beta$ [22]. In our study, we found that the hepatic mRNA levels of TGF- $\beta$ and IL-10 were significantly elevated in the S. japonicum-infected mice when compared with normal WT mice, and a further increasing mRNA expression was observed in the fucoidantreated S. japonicum-infected group (ANOVA test; TGF- $\beta$ : $F_{(3,23)}=15.72, P<0.0001 ; \mathrm{IL}-10: F_{(3,23)}=25.13$, $P<0.0001$ ) (Fig. 6a, b). Similar results were also observed in vitro stimulated macrophages, namely an uptrend after fucoidan treatment (t-test; TGF- $\beta$ : $t_{(8)}=3.689, P=0.006$; IL-10: $t_{(8)}=3.617, P=0.0063$ ) (Fig. 6c, d).

A wide array of functional surface molecules on Treg cells assists Tregs in accomplishing their migratory, antiinflammatory and immunosuppressive functions in the immune environment [23]. To investigate the suppressive function of Treg cells, we next determined surface molecules relatively specific to Treg cells induced by fucoidan (Fig. 6e). CCR4, the CC chemokine receptor principally involved in homing of $\mathrm{T}$ cells to inflammatory sites [24], increased on $\mathrm{CD} 4{ }^{+} \mathrm{CD} 25^{+}$Tregs in the presence of fucoidan compared to the control group ( $\mathrm{t}$-test; $t_{(6)}=5.326, P=0.002$ ) (Fig. 6f). CCR5 is also involved in immunosuppression and migration $[25,26]$, and significantly, the proportion of CCR $5^{+}$Tregs increased ( $\mathrm{t}$-test; $t_{(5)}=7.948, P<0.001$ ) (Fig. $6 \mathrm{~g}$ ). However, there were no remarkable differences in the other Treg-associated

(See figure on next page.)

Fig. 2 Fucoidan suppresses inflammation in the livers from S. japonicum-infected mice. Quantitative real-time PCR analysis of IL-6 (a), IL-12 (b), TNF-a (c), IL-13 (d) and IL-4 (e) in each group. The liver tissues of each group were prepared. The mRNA levels of inflammatory cytokines in the liver of each group were evaluated. The mRNA level of each gene was normalized to GAPDH mRNA levels in each sample. Results are presented using the $2^{-\triangle \triangle C q}$ method. $\mathbf{f} I$ mmunofluorescence of Pho-p65 in the liver tissue from normal or S. japonicum-infected mice treated with or without fucoidan. Original magnification: $\times 200$. g The mean optical density of Pho-p65 positive cells from 6 random fields in each group was digitized and analyzed using Image-Pro Plus software. Data are expressed as the mean \pm SD for each group ( $n=5$ for each group), and all experiments were

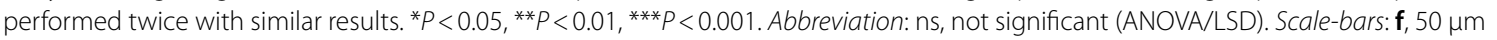



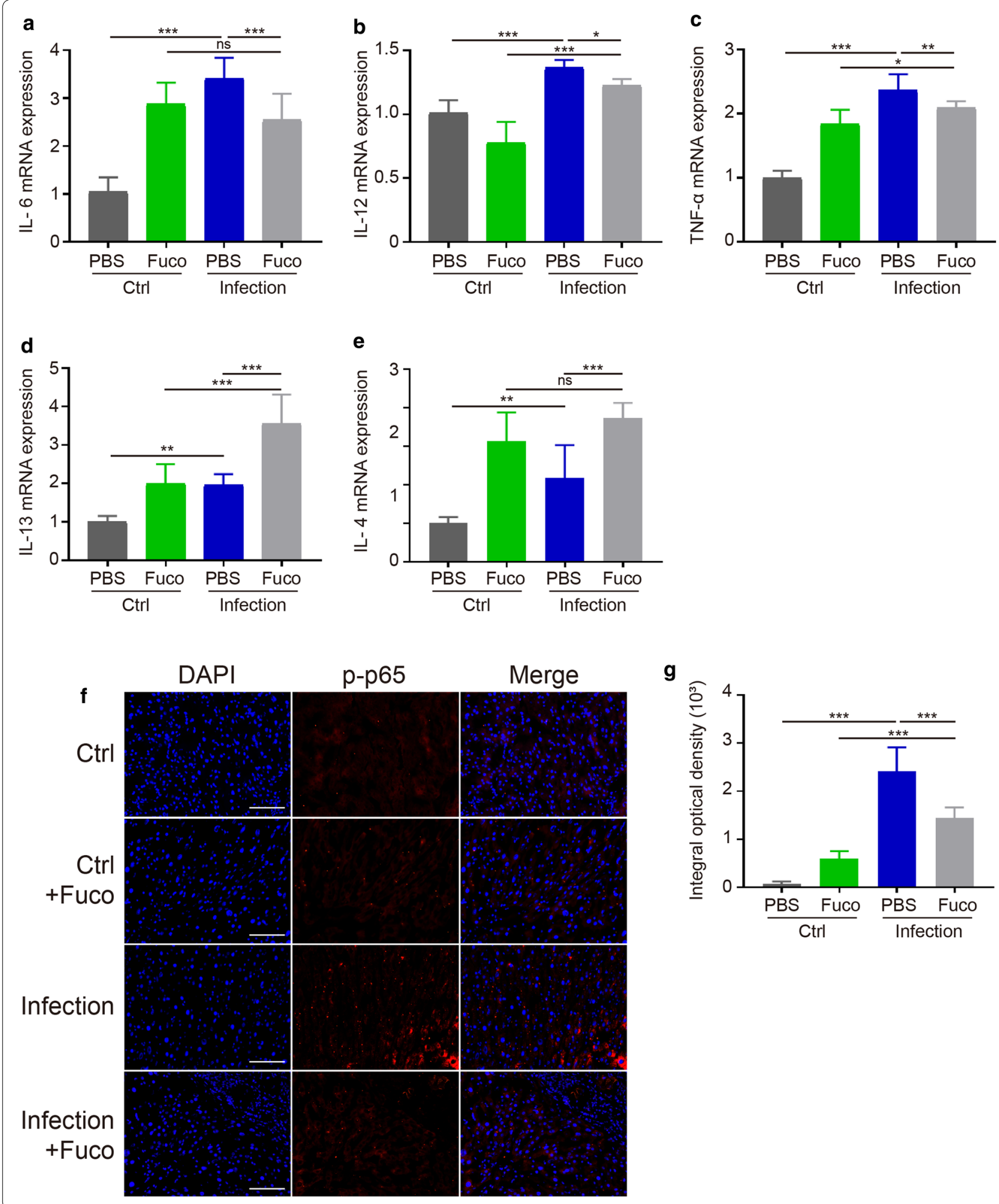

g

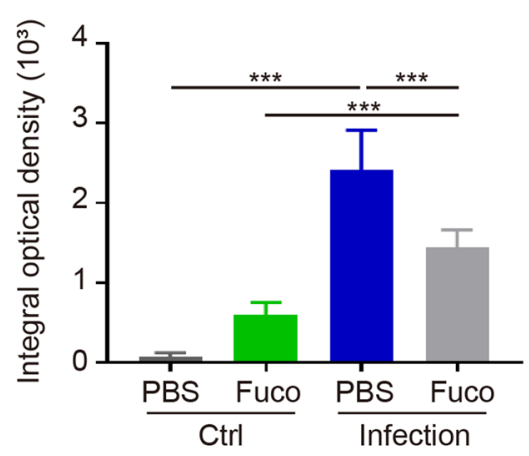



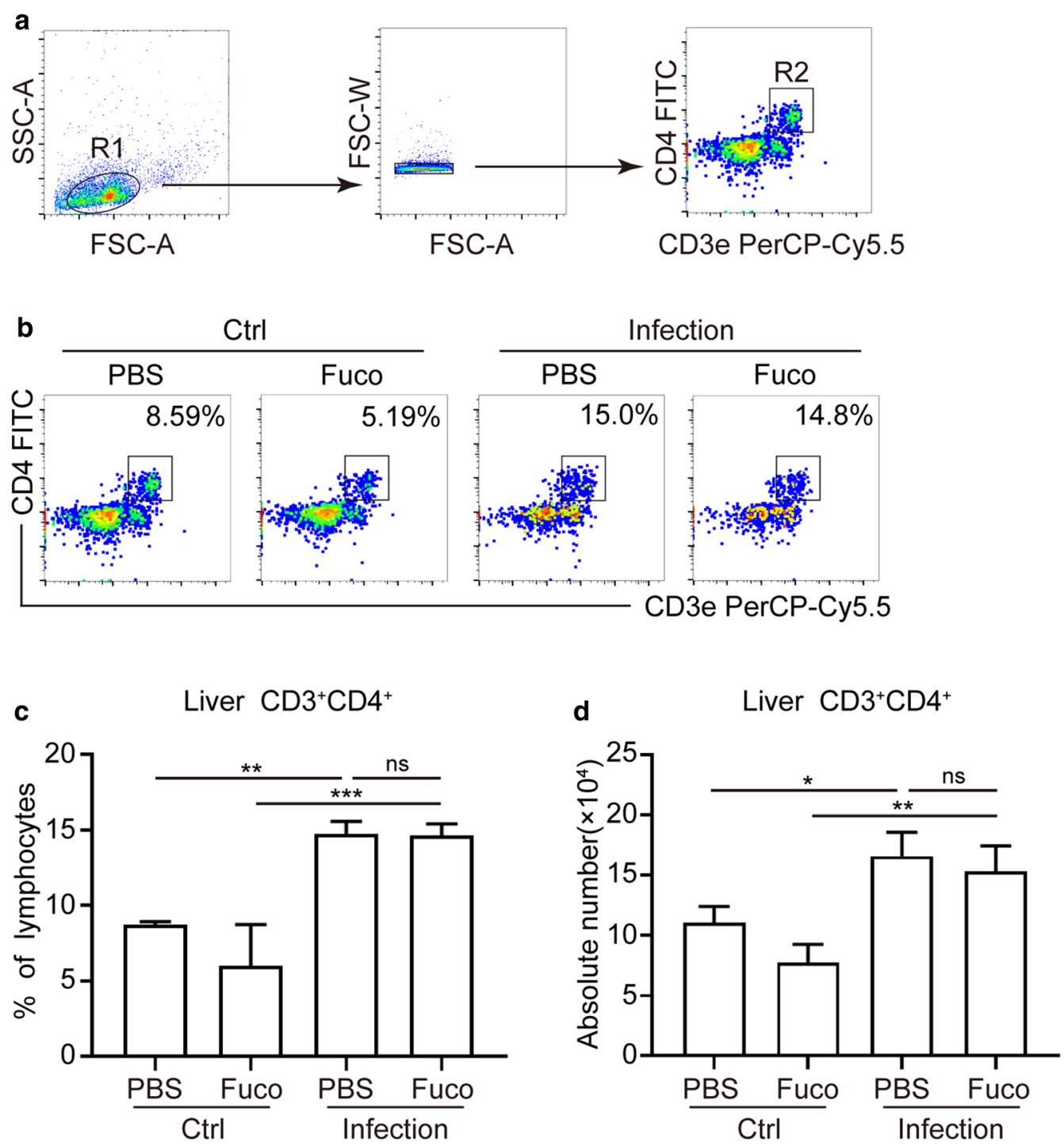

Fig. 3 Flow cytometry analysis of total $\mathrm{CD}^{+} \mathrm{CD}^{+} \mathrm{T}$ cells in mice. a Gating strategy for $\mathrm{CD} 3^{+} \mathrm{CD} 4^{+} \mathrm{T}$ cells in the livers. b Representative flow cytometry gates from liver tissues are presented. $\mathbf{c}, \mathbf{d}$ The percentage and the absolute number of $\mathrm{CD}^{+} \mathrm{CD} 4^{+}$cells from hepatic lymphocytes of each group were analyzed by flow cytometry. Data are expressed as the mean $\pm S D$ for each group ( $n=5$ for each group), and all experiments were performed twice with similar results. ${ }^{*} P<0.05,{ }^{* *} P<0.01,{ }^{* * *} P<0.001$. Abbreviation: ns, not significant (ANOVA/LSD)

\section{(See figure on next page.)}

Fig. 4 Analysis of $\mathrm{CD}^{+}$T cell subsets in mice after fucoidan treatment. a Immunofluorescence of CD4 (green) and Foxp3 (red) in the liver granulomas from the normal or S. japonicum-infected mice treated with or without fucoidan. Original magnification: $\times 400$. b The mean optical density of $\mathrm{CD} 4^{+} \mathrm{Foxp}^{+}$cells in each group was digitized and analyzed using Image-Pro Plus software. c Gating strategy for $\mathrm{CD}^{+} \mathrm{CD}^{+}{ }^{+}$Foxp3 ${ }^{+}$ (Treg), $\mathrm{CD}^{+} \mathrm{CD}^{+} \mathrm{IL}-17^{+}$(Th17), $\mathrm{CD} 3^{+} \mathrm{CD} 4^{+} \mathrm{IFN}-\gamma^{+}$(Th1) and $\mathrm{CD} 3^{+} \mathrm{CD} 4^{+} \mathrm{IL}-4^{+}$(Th2) cells. Percentages and absolute numbers of Treg (d), Th17 (e), Th1 $\mathbf{( f )}$ and Th2 $\mathbf{( g )}$ cells from hepatic or splenic lymphocytes of each group were analyzed by flow cytometry. Data are expressed as the mean \pm SD for each group ( $n=5$ for each group), and all experiments were performed twice with similar results. ${ }^{*} P<0.05,{ }^{* *} P<0.01,{ }^{* * *} P<0.001$. Abbreviation: ns, not significant (ANOVA/LSD). Scale-bars: a, $25 \mu \mathrm{m}$ 


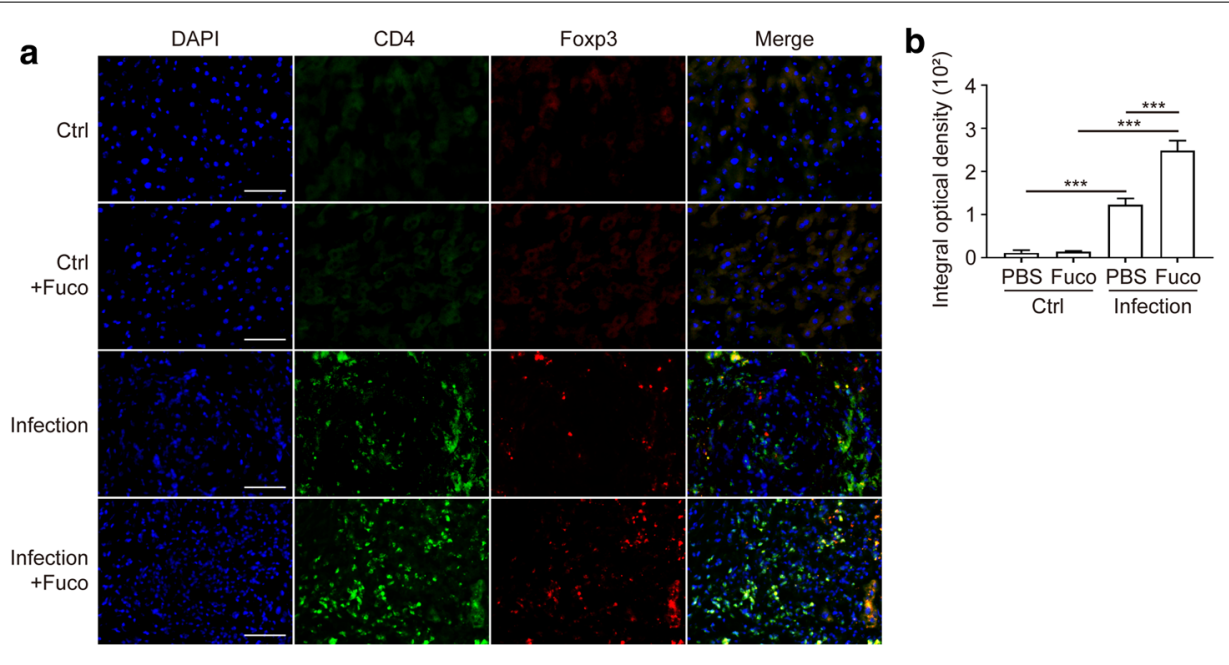

C
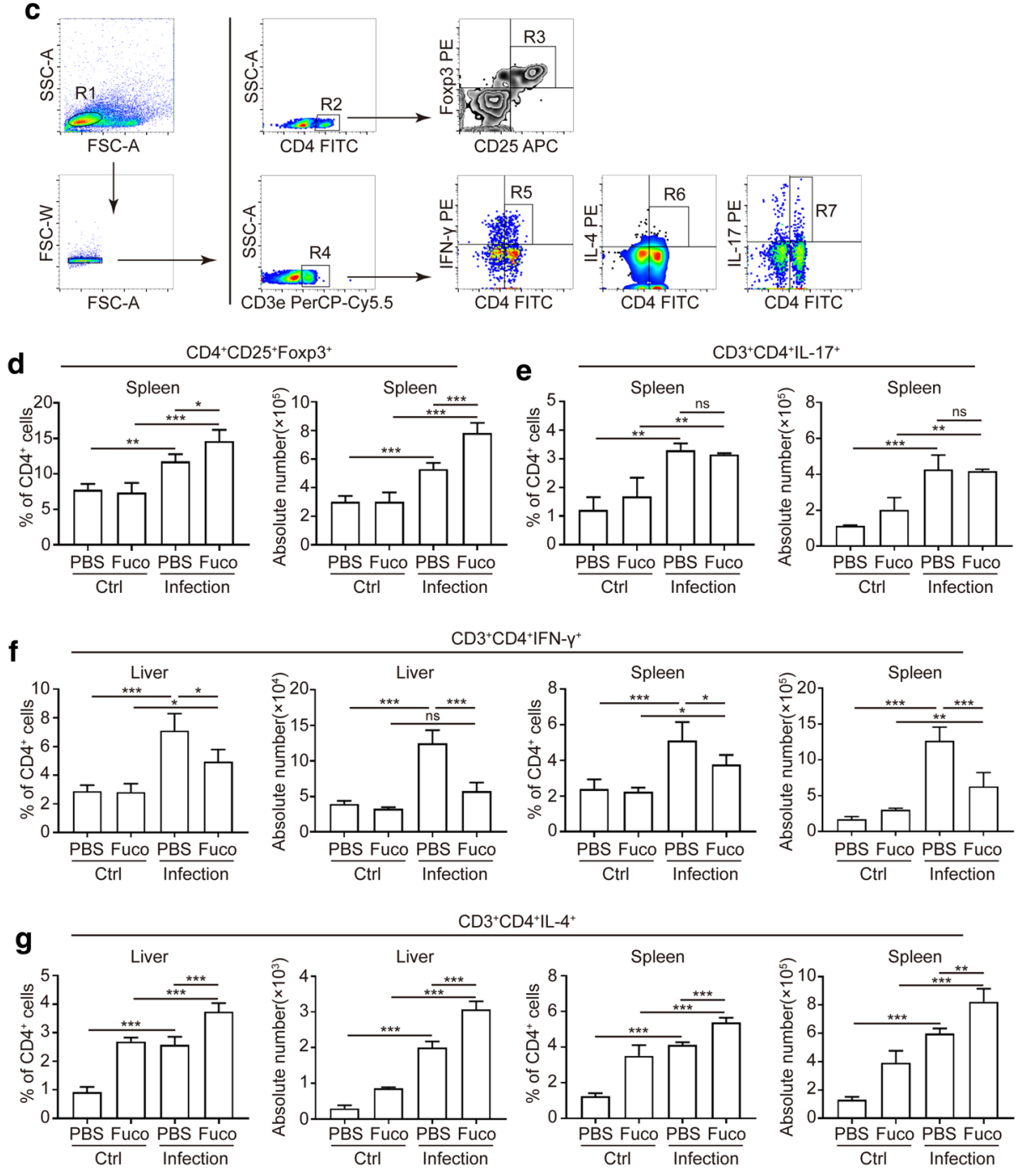

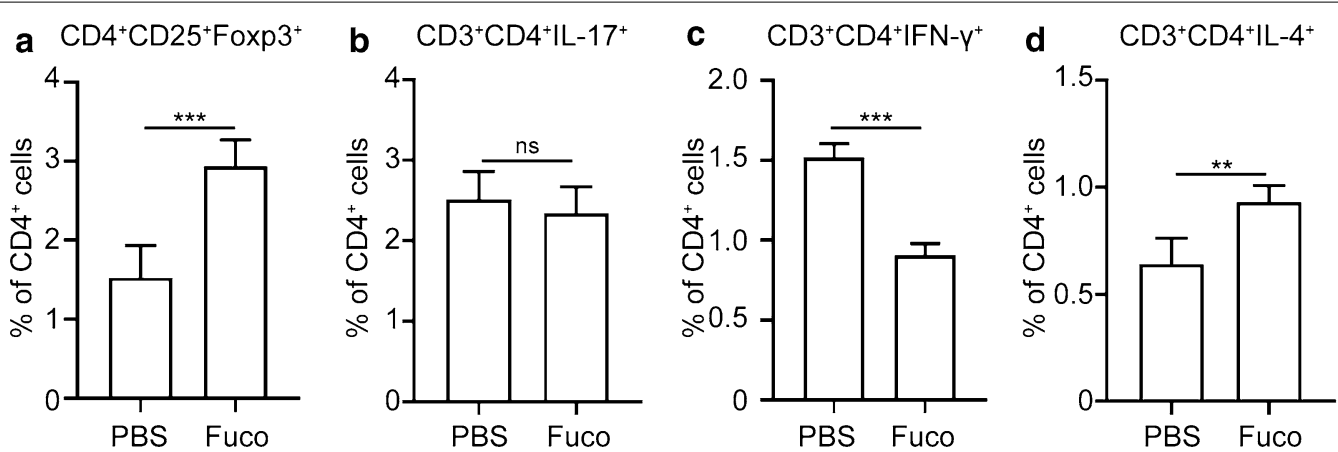

Fig. 5 Flow cytometry analysis of subsets of $\mathrm{CD}^{+}{ }^{+} \mathrm{T}$ cells in vitro. Percentage of Treg (a), Th17 (b), Th1 (c) and Th2 (d) cells were analyzed by flow cytometry. Data are expressed as the mean \pm SD for each group $(n=5$ for each group), and all experiments were performed twice with similar results. ${ }^{*} P<0.05,{ }^{* *} P<0.01,{ }^{* * *} P<0.001$. Abbreviation: ns, not significant (Student's t-test)
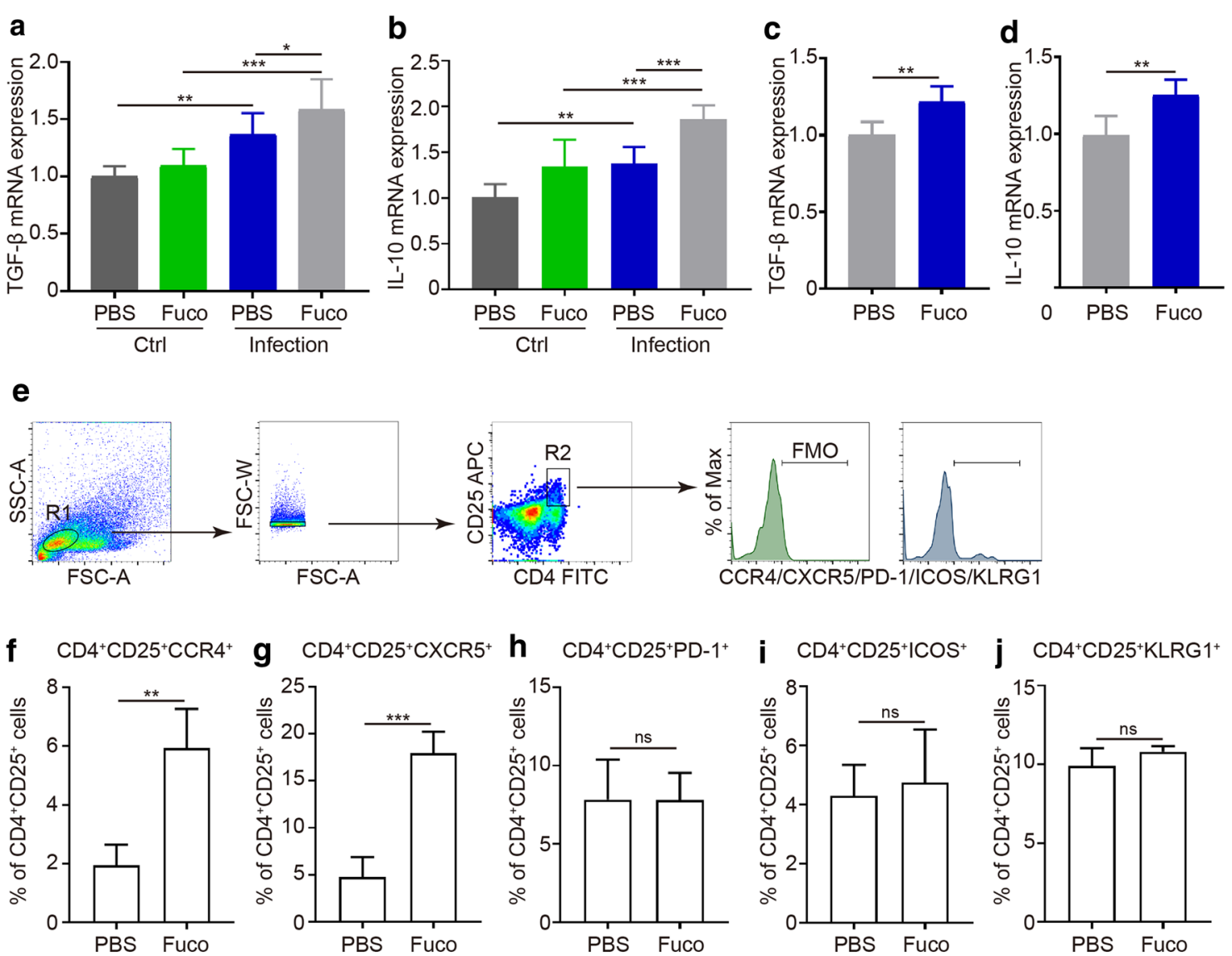

Fig. 6 Fucoidan enhances immunosuppressive properties in Treg cells. qRT-PCR analysis of TGF- $\beta$ and IL-10 in liver tissues (a, b) and RAW264.7 cells (c, d). The mRNA level of each gene was normalized to GAPDH mRNA levels in each sample. Results are presented using the $2^{-\triangle \Delta C q}$ method. $\mathbf{e}$

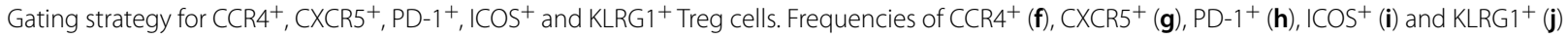
Treg cells were analyzed by flow cytometry. All flow cytometry results were analyzed and plotted using Fluorescence Minus One controls (FMO). Data are expressed as the mean \pm SD for each group ( $n=5$ for each group), and all experiments were performed twice with similar results. ${ }^{*} P<0.05$, ${ }^{* *} P<0.01,{ }^{* *} P<0.001$. Abbreviation: ns, not significant (Student's t-test, ANOVA/LSD) 
markers, such as PD-1, ICOS and KLRG1, after fucoidan treatment (t-test; PD-1: $t_{(6)}=0.02423, P=0.98$; ICOS: $\left.t_{(6)}=0.4304, \quad P=0.68 ; \quad K L R G 1: \quad t_{(5)}=1.308, \quad P=0.25\right)$ (Fig. 6h-j). These results indicate that fucoidan has the potential immunosuppressive activity of Treg cells characterized by the expression of CCR4 and CXCR5.

\section{Fucoidan promotes anti-inflammatory response in macrophages}

Since macrophages play a pivotal role in regulating pathogenesis in schistosomiasis japonica [2], we next investigated whether fucoidan could induce changes in macrophage response. Results showed that stimulation with fucoidan resulted in an M2-dominant phenotype, as evidenced by increased expression of anti-inflammatory cytokines (IL-4 and IL-13) (t-test; IL-4: $t_{(8)}=3.075$, $P=0.02$; IL-13: $t_{(7)}=3.210, P=0.0149$ ) (Additional file 3: Figure S2d, e), rather than classically activated macrophage (M1)-related cytokines (IL-6, IL-12 and TNF- $\alpha$ ) (t-test; IL-6: $t_{(8)}=5.054, P=0.0010 ;$ IL-12: $t_{(8)}=7.994$, $P<0.0001$; TNF- $\alpha: t_{(8)}=3.852, \quad P=0.005$ ) (Additional file 3: Figure $\mathrm{S} 2 \mathrm{a}-\mathrm{c}$ ). These data suggest the potential role of fucoidan in mediating the anti-inflammatory effects during pathogen infection.

\section{Discussion}

Fucoidan, mainly extracted from brown seaweed, is a complex sulfated polysaccharide that exhibits a wide spectrum of biological activities including anti-inflammatory, anticancer, antioxidant, anticoagulant, antiviral and immunomodulatory [27]. Especially in the modulation of immunity, fucoidan can be used as a tool to terminate various disease processes, such as viral and bacterial infections [28]. It has been reported that fucoidan can activate cytotoxic $\mathrm{T}$ cells, and further research demonstrates that fucoidan enhances dendritic cell maturation and promote immune response [29, 30]. These studies have highlighted fucoidan can attenuate the immunopathology by encouraging both innate and adaptive immune responses. However, to the best of our knowledge, how fucoidan regulates $\mathrm{CD} 4^{+} \mathrm{T}$ cells immune responses during $S$. japonicum infection has not been fully elucidated. We demonstrated for the first time that fucoidan could attenuate S. japonicum-induced liver pathology and blockage of the inflammatory response associated with the strong immunosuppressive function of Treg cells.

Schistosomiasis is a parasitic disease caused by infection with several species of schistosome trematodes, affecting over 200 million people worldwide [31]. During $S$. japonicum infection, parasite eggs are trapped within organs such as the liver, spleen and intestine, which contributes to severe granulomatous inflammation and fibrosis formation [3, 32]. An early report has demonstrated that fucoidan could attenuate $\mathrm{CCl}_{4}$-induced liver fibrosis [33]. However, to the best of our knowledge, there are no studies of fucoidan on liver disease resulting from natural infection. In the present study, granulomatous size and fibrosis response in the liver were significantly decreased after treated with fucoidan in a $S$. japonicum-infected mouse model. Therefore, we suppose that fucoidan plays a role in the suppression of hepatic immunopathology during natural pathogen infection.

The process of egg granuloma formation and fibrosis is dependent upon the immune microenvironment, particularly specific cytokine production [34, 35]. Here we observed an anti-inflammatory phenotype in the liver from the fucoidan-treated infection group, indicating that fucoidan could exert a suppressive influence on hepatic inflammation. The NF- $\mathrm{kB}$ signaling activation plays a pivotal role in inflammation induction and regulation [36, 37]. Activation of the NF- $\mathrm{kB}$ signal pathway had been reported to be closely associated with the development of hepatic granuloma and fibrosis [38]. Interestingly, fucoidan has been reported to attenuate the expression of NF- $\mathrm{BB}$ in the hepatic tissues from a NAFLD mice model [37]. Importantly, a recent study has also confirmed that fucoidan could inhibit LPS-induced inflammation and pro-inflammatory cytokine mRNA expression in macrophage by blocking the TLR4/NF-kB signal pathway [16]. Our study provided evidence that fucoidan may reduce liver granuloma and fibrosis at least partly due to the decreased TLR $4 / N F-\kappa B$ signaling pathway, evidenced by the weakened expressed Pho-p65.

Numerous studies have shown that $\mathrm{CD}^{+} \mathrm{T}$ cells are the predominant contributors to inflammatory responses and the regulators of hepatic granuloma and fibrosis in schistosomiasis [18, 21]. Moreover, fucoidan has been reported to activate the growth of $\mathrm{T}$ and $\mathrm{B}$ cells in the spleen $[39,40]$, and we further speculated that fucoidan could alleviate hepatic immunopathology by affecting the subsets of CD $4^{+} \mathrm{T}$ cells. Remarkably, Treg cells are widely recognized to respond to local milieu to behave as subtypes that are equipped with distinct immunosuppressive programs to function in inflammatory settings. Corresponding with the previous study about Treg cells relieving hepatic inflammatory responses and immunopathology in schistosomiasis japonica [41], we found that fucoidan induced Treg cells expansion, which might contribute to the attenuated hepatic immunopathology during $S$. japonicum infection. Meanwhile, results of qRT-PCR also showed ascending expression of TGF- $\beta$ and IL-10 both in vivo and in vitro treated with fucoidan, principally due to the enhanced immunosuppressive microenvironment induced by Treg cells. Previous studies showed that the process of granuloma depositing and fibrosis 
is triggered with an initial Th1-dominant response to a late Th2-dominant response [42, 43]. However, our data showed that Th 2 cells were expanded, whereas Th 1 cells were reduced in the presence of fucoidan during $S$. japonicum infection. We speculated that the abnormal Th1/Th2 response induced by fucoidan might play a subordinate role in this process.

To function properly, Treg cells regulate the activities of a wide range of cellular molecules, namely chemokine receptors, programmed cell death-1 (PD-1) and inducible co-stimulatory molecules (ICOS) [23]. The important role of these surface molecules and their association with inflammatory responses has been widely documented in both animal models and human samples. For example, CCR4-deficient Treg cells fail to migrate, causing severe inflammatory diseases in the lungs, intestines and other nonlymphoid organs $[44,45]$. CXCR $5^{+}$follicular regulatory (Tfr) cells, an especially-classified thymic-derived Foxp3 ${ }^{+}$Tregs, are reported to increase within $\mathrm{CD} 4^{+} \mathrm{T}$ cells and total Tfh cells in schistosomiasis patients [46]. Tregs lacking CXCR5 show impaired suppressive function and cause enhanced germinal center responses [47]. In our findings, both CCR4 ${ }^{+}$and $\mathrm{CXCR} 5^{+}$Tregs increased after fucoidan treatment, while no variations were observed on the expressions of PD-1, ICOS, and KLRG1. Hence, the enhanced immunosuppressive activity induced by fucoidan may be related to the functional expressions of CCR4 and CXCR5 on Treg cells, thus relieving the hepatic inflammatory response and resultant process of granuloma and fibrosis.

The granulomatous immune response is also characterized by complicated cells, such as macrophages, which account for approximately $30 \%$ of granuloma cells $[48,49]$. A previous study showed that IFN- $\gamma$, the product of Th1 cells and acting predominantly on macrophages to drive M1 differentiation, which secret various pro-inflammatory cytokines, such as TNF- $\alpha$, IL- 6 and IL-12, and activate the adaptive immune response [50]. High levels of IL-4 and IL-13, which can be secreted primarily by type- 2 immune cells such as Th2 cells to act toward the alternative activation of macrophages into the M2 phenotype [50,51]. Our in vitro study suggested that the increased M2 macrophages polarization induced by fucoidan was probably due to the enhanced Th2 cells, while the declined M1 macrophages related to the decreased Th1 cells. A previous study showed that fucoidan is the ligand of scavenger receptor A (SR-A) [52], which has been found to promote the liver pathology through inducing M2 macrophages and Th2 cell response during S. japonicum infection [10]. However, our data indicate the fucoidan attenuated liver pathology, one possible explanation is that fucoidan acts on not only SR-A but also TLR4 pathway [16], the latter of which activates the production of pro-inflammatory cytokines and might be the potential mechanism in the present study, which requires further elucidated in the future.

\section{Conclusions}

In summary, this study indicates that fucoidan can effectively alleviate hepatic immunopathology during $S$. japonicum infection, one possible mechanism of which is that fucoidan regulates $\mathrm{CD} 4^{+} \mathrm{T}$ cells dominated by immunosuppressive functions of Tregs. Our data provide a novel insight into the biological functions of fucoidan from an immunomodulatory perspective, particularly its regulatory effects on the immune response.

\section{Supplementary information}

Supplementary information accompanies this paper at https://doi. org/10.1186/s13071-020-04332-7.

Additional file 1: Table S1. The primer sequences used in detecting the levels of mRNA.

Additional file 2: Figure S1. Flow cytometry of total $\mathrm{CD}^{+} \mathrm{CD} 4^{+} \mathrm{T}$ cells in spleens.

Additional file 3: Figure S2. The mRNA expression of cytokines in fucoidan-treated macrophages.

\section{Abbreviations}

CCR4: CC chemokine receptor type 4; CXCR5: CXC chemokine receptor type 5; IL: interleukin; NF-KB: nuclear factor-KB; TGF- $\beta$ : transforming growth factor- $\beta$;

Th cell: helper T cell; TNF-a: tumor necrosis factor-a; Treg cell: regulatory $T$ cell.

\section{Acknowledgements}

We thank all authors mentioned above for their devotion to this work.

\section{Authors' contributions}

$\mathrm{ZPX}$ and MJJ conceived and designed the experiments. $\mathrm{XQB}, \mathrm{XYW}, \mathrm{MNL}, \mathrm{HC}$, YYN, CL, KYH, HQW, YXY, TT and MH carried out the animal experiments. XQB participated in analyzing the data. XQB and ZPX drafted the manuscript. All authors read and approved the final manuscript.

\section{Funding}

This study was supported by the National Natural Science Foundation of China (grant No. 81702023); The Natural Science Foundation of Jiangsu Province (Grant No. BK20171049). Technology Development Foundation of Nanjing Medical University (Grant No. NMUB2018292); Jiangsu Students' Platform for Innovation and Entrepreneurship Training Program (Grant No. 201910312013Z).

\section{Availability of data and materials}

The data that support the findings of this study are included in the article and its additional files. 


\section{Ethics approval and consent to participate}

All animal studies and experimental procedures were in strict accordance with the Regulations for the Care and Use of Laboratory Animals (National Institutes of Health Publication No. 85-23, revised 1985). All experiments were approved by the Institutional Animal Care and Use Committee of Nanjing Medical University for the use of laboratory animals (IACUC-1903034).

\section{Consent for publication}

Not applicable.

\section{Competing interests}

The authors declare that they have no competing interests.

\section{Author details}

1 Department of Pathogen Biology, Jiangsu Province Key Laboratory of Modern Pathogen Biology, Nanjing Medical University, Nanjing, Jiangsu 211166 , China. ${ }^{2}$ Department of Dermatology, The Affiliated Sir Run Run Hospital of Nanjing Medical University, Nanjing, Jiangsu 211100, China.

Received: 29 June 2020 Accepted: 30 August 2020

Published online: 07 September 2020

\section{References}

1. McManus DP, Dunne DW, Sacko M, Utzinger J, Vennervald BJ, Zhou XN. Schistosomiasis. Nat Rev Dis Primers. 2018;4:13.

2. Chuah C, Jones MK, Burke ML, McManus DP, Gobert GN. Cellular and chemokine-mediated regulation in schistosome-induced hepatic pathology. Trends Parasitol. 2014;30:141-50.

3. Colley DG, Bustinduy AL, Secor WE, King CH. Human schistosomiasis. Lancet. 2014;383:2253-64.

4. Fallon PG, Dunne DW. Tolerization of mice to Schistosoma mansoni egg antigens causes elevated type 1 and diminished type 2 cytokine responses and increased mortality in acute infection. J Immunol. 1999;162:4122-32.

5. Zhou S, Qi Q, Wang X, Zhang L, Xu L, Dong L, et al. SjHSP60 induces CD4(+) CD25(+) Foxp3(+) Tregs via TLR4-Mal-drived production of TGFbeta in macrophages. Immunol Cell Biol. 2018;96:958-68.

6. He L, Zhou S, Qi Q, Chi Y, Zhu J, Xu Z, et al. The regulation of regulation: interleukin-10 increases CD4(+) CD25(+) regulatory T cells but impairs their immunosuppressive activity in murine models with schistosomiasis japonica or asthma. Immunology. 2018;153:84-96.

7. Chuah C, Jones MK, McManus DP, Nawaratna SK, Burke ML, Owen HC, et al. Characterising granuloma regression and liver recovery in a murine model of schistosomiasis japonica. Int J Parasitol. 2016:46:239-52.

8. Sandler NG, Mentink-Kane MM, Cheever AW, Wynn TA. Global gene expression profiles during acute pathogen-induced pulmonary inflammation reveal divergent roles for Th1 and Th2 responses in tissue repair. J Immunol. 2003;171:3655-67.

9. Cheng PC, Lin CN, Peng SY, Li LL, Luo TY, Fan CK, et al. A study of immunomodulatory genes responses to macrophages of Schistosoma japonicum infection during different stages by microarray analysis. Acta Trop. 2013;127:251-60.

10. Xu Z, Xu L, Li W, Jin X, Song X, Chen X, et al. Innate scavenger receptor-A regulates adaptive $T$ helper cell responses to pathogen infection. Nat Commun. 2017:8:16035.

11. Herbert DR, Holscher C, Mohrs M, Arendse B, Schwegmann A, Radwanska $M$, et al. Alternative macrophage activation is essential for survival during schistosomiasis and downmodulates Thelper 1 responses and immunopathology. Immunity. 2004;20:623-35.

12. Vishchuk OS, Ermakova SP, Zvyagintseva TN. The fucoidans from brown algae of Far-Eastern seas: anti-tumor activity and structure-function relationship. Food Chem. 2013:141:1211-7.

13. Park MK, Jung U, Roh C. Fucoidan from marine brown algae inhibits lipid accumulation. Mar Drugs. 2011:9:1359-67.

14. Kwak JY. Fucoidan as a marine anticancer agent in preclinical development. Mar Drugs. 2014:12:851-70.
15. Lee $\mathrm{SH}, \mathrm{Ko} \mathrm{Cl}$, Jee $\mathrm{Y}$, Jeong $\mathrm{Y}, \mathrm{Kim} \mathrm{M}$, Kim JS, et al. Anti-inflammatory effect of fucoidan extracted from Ecklonia cava in zebrafish model. Carbohydrate polymers. 2013:92:84-9.

16. Asanka Sanjeewa KK, Jayawardena TU, Kim HS, Kim SY, Shanura Fernando IP, Wang $L$, et al. Fucoidan isolated from Padina commersonii inhibit LPSinduced inflammation in macrophages blocking TLR/NF-kappaB signal pathway. Carbohydrate polymers. 2019;224:115195.

17. Yu HH, Chengchuan Ko E, Chang CL, Yuan KS, Wu ATH, Shan YS, et al. Fucoidan inhibits radiation-induced pneumonitis and lung fibrosis by reducing inflammatory cytokine expression in lung tissues. Mar Drugs. 2018;16:392.

18. Zhu Y, Ni Y, Liu R, Hou M, Yang B, Song J, et al. PPAR-gamma agonist alleviates liver and spleen pathology via inducing Treg cells during Schistosoma japonicum infection. J Immunol Res. 2018;2018:6398078.

19. Lim JD, Lee SR, Kim T, Jang SA, Kang SC, Koo HJ, et al. Fucoidan from Fucus vesiculosus protects against alcohol-induced liver damage by modulating inflammatory mediators in mice and HepG2 cells. Mar Drugs. 2015:13:1051-67.

20. Gong WC, Huang FJ, Sun L, Yu AP, Zhang XF, Xu YX, et al. Toll-like receptor-2 regulates macrophage polarization induced by excretory-secretory antigens from Schistosoma japonicum eggs and promotes liver pathology in murine schistosomiasis. PLoS Negl Trop D. 2018;12:e0007000.

21. Pearce EJ, MacDonald AS. The immunobiology of schistosomiasis. Nat Rev Immunol. 2002;2:499-511.

22. Kanamori M, Nakatsukasa H, Okada M, Lu Q, Yoshimura A. Induced regulatory $T$ cells: their development, stability, and applications. Trends Immunol. 2016:37:803-11.

23. Campbell DJ, Koch MA. Phenotypical and functional specialization of FOXP3+ regulatory T cells. Nat Rev Immunol. 2011;11:119-30.

24. Yoshie O, Matsushima K. CCR4 and its ligands: from bench to bedside. Int Immunol. 2015:27:11-20.

25. Lee BP, Chen W, Shi H, Der SD, Forster R, Zhang L. CXCR5/CXCL13 interaction is important for double-negative regulatory $T$ cell homing to cardiac allografts. J Immunol. 2006;17:5276-83.

26. Sayin I, Radtke AJ, Vella LA, Jin W, Wherry EJ, Buggert M, et al. Spatial distribution and function of $\mathrm{T}$ follicular regulatory cells in human lymph nodes. J Exp Med. 2018;215:1531-42.

27. Wang $Y$, Xing $M$, Cao Q, Ji A, Liang H, Song S. Biological activities of fucoidan and the factors mediating its therapeutic effects: a review of recent studies. Mar Drugs. 2019;17:183.

28. Tang Y, Li H, Li J, Liu Y, Li Y, Zhou J, et al. Macrophage scavenger recepto 1 contributes to pathogenesis of fulminant hepatitis via neutrophilmediated complement activation. J Hepatol. 2018;68:733-43.

29. Jin JO, Zhang W, Du JY, Wong KW, Oda T, Yu Q. Fucoidan can function as an adjuvant in vivo to enhance dendritic cell maturation and function and promote antigen-specific T cell immune responses. PLoS One. 2014;9:e99396.

30. Zhang W, Du JY, Jiang Z, Okimura T, Oda T, Yu Q, et al. Ascophyllan purified from Ascophyllum nodosum induces Th1 and Tc1 immune responses by promoting dendritic cell maturation. Mar Drugs. 2014;12:4148-64.

31. McManus DP. Defeating schistosomiasis. N Engl J Med. 2019;381:2567-8.

32. Anthony BJ, Ramm GA, McManus DP. Role of resident liver cells in the pathogenesis of schistosomiasis. Trends Parasitol. 2012;28:572-9.

33. Hayashi S, Itoh A, Isoda K, Kondoh M, Kawase M, Yagi K. Fucoidan partly prevents CCl4-induced liver fibrosis. Eur J Pharmacol. 2008;580:380-4.

34. Zhu J, Zhang W, Zhang L, Xu L, Chen X, Zhou S, et al. IL-7 suppresses macrophage autophagy and promotes liver pathology in Schistosoma japonicum-infected mice. J Cell Mol Med. 2018;22:3353-63.

35. Chen D, Xie H, Cha H, Qu J, Wang M, Li L, et al. Characteristics of Schistosoma japonicum infection induced IFN-gamma and IL-4 co-expressing plasticity Th cells. Immunology. 2016;149:25-34.

36. Luedde T, Schwabe RF. NF-kappaB in the liver-linking injury, fibrosis and hepatocellular carcinoma. Nat Rev Gastroenterol Hepatol. 2011;8:108-18.

37. Zheng Y, Liu T, Wang Z, Xu Y, Zhang Q, Luo D. Low molecular weight fucoidan attenuates liver injury via SIRT1/AMPK/PGC1alpha axis in db/db mice. Int J Biol Macromol. 2018;112:929-36.

38. Wan C, Jin F, Du Y, Yang K, Yao L, Mei Z, et al. Genistein improves schistosomiasis liver granuloma and fibrosis via dampening NF-kB signaling in mice Parasitol Res. 2017:116:1165-74 
39. Tomori M, Nagamine T, Miyamoto T, Iha M. Evaluation of the immunomodulatory effects of fucoidan derived from Cladosiphon okamuranus Tokida in mice. Mar Drugs. 2019;17:547.

40. Tian T, Chang H, He K, Ni Y, Li C, Hou M, et al. Fucoidan from seaweed Fucus vesiculosus inhibits 2,4-dinitrochlorobenzene-induced atopic dermatitis. Int Immunopharmacol. 2019;75:105823.

41. Hesse M, Piccirillo CA, Belkaid Y, Prufer J, Mentink-Kane M, Leusink M, et al. The pathogenesis of schistosomiasis is controlled by cooperating IL-10-producing innate effector and regulatory T cells. J Immunol. 2004;172:3157-66.

42. Sher A, Fiorentino D, Caspar P, Pearce E, Mosmann T. Production of IL-10 by CD4+ T lymphocytes correlates with down-regulation of Th1 cytokine synthesis in helminth infection. J Immunol. 1991;147:2713-6.

43. Kaplan MH, Whitfield JR, Boros DL, Grusby MJ. Th2 cells are required for the Schistosoma mansoni egg-induced granulomatous response. J Immunol. 1998;160:1850-6.

44. Al-Banna NA, Vaci M, Slauenwhite D, Johnston B, Issekutz TB. CCR4 and CXCR3 play different roles in the migration of $T$ cells to inflammation in skin, arthritic joints, and lymph nodes. Eur J Immunol. 2014;44:1633-43.

45. Yuan Q, Bromley SK, Means TK, Jones KJ, Hayashi F, Bhan AK, et al. CCR4dependent regulatory $T$ cell function in inflammatory bowel disease. J Exp Med. 2007;204:1327-34.

46. Chen X, Li W, Zhang Y, Song X, Xu L, Xu Z, et al. Distribution of peripheral memory $T$ follicular helper cells in patients with schistosomiasis japonica. PLoS Negl Trop Dis. 2015;9:e0004015.
47. Chung Y, Tanaka S, Chu F, Nurieva RI, Martinez GJ, Rawal S, et al. Follicular regulatory $T$ cells expressing Foxp3 and Bcl-6 suppress germinal center reactions. Nat Med. 2011;17:983-8.

48. Hernandez HJ, Wang Y, Tzellas N, Stadecker MJ. Expression of class II, but not class I, major histocompatibility complex molecules is required for granuloma formation in infection with Schistosoma mansoni. Eur J Immunol. 1997;27:1170-6.

49. Burke ML, Jones MK, Gobert GN, Li YS, Ellis MK, McManus DP. Immunopathogenesis of human schistosomiasis. Parasite Immunol. 2009;31:163-76.

50. Xu J, Zhang H, Chen L, Zhang D, Ji M, Wu H, et al. Schistosoma japonicum infection induces macrophage polarization. J Biomed Res. 2014;28:299-308

51. Kamdem SD, Moyou-Somo R, Brombacher F, Nono JK. Host regulators of liver fibrosis during human schistosomiasis. Front Immunol. 2018;9:2781.

52. van Oosten $M$, van de Bilt E, van Berkel TJ, Kuiper J. New scavenger receptor-like receptors for the binding of lipopolysaccharide to liver endothelial and Kupffer cells. Infect Immun. 1998;66:5107-12.

\section{Publisher's Note}

Springer Nature remains neutral with regard to jurisdictional claims in published maps and institutional affiliations.
Ready to submit your research? Choose BMC and benefit from:

- fast, convenient online submission

- thorough peer review by experienced researchers in your field

- rapid publication on acceptance

- support for research data, including large and complex data types

- gold Open Access which fosters wider collaboration and increased citations

- maximum visibility for your research: over 100M website views per year

At BMC, research is always in progress.

Learn more biomedcentral.com/submissions 